\title{
X-ray tomography of large wooden artworks: the case study of "Doppio corpo" by Pietro Piffetti
}

\author{
Alessandro Re ${ }^{1,2^{*}}$, Fauzia Albertin ${ }^{1}$, Chiara Avataneo ${ }^{2}$, Rosa Brancaccio ${ }^{1}$, Jacopo Corsi ${ }^{1,2}$, Giorgio Cotto ${ }^{1,2}$, \\ Stefania De Blasi ${ }^{3}$, Giovanni Dughera ${ }^{1}$, Elisabetta Durisi ${ }^{1,2}$, Walter Ferrarese ${ }^{1,2}$, Annamaria Giovagnoli ${ }^{3}$, \\ Novella Grassi ${ }^{3}$, Alessandro Lo Giudice ${ }^{1,2}$, Paolo Mereu', Giorgia Mila ${ }^{1,2}$, Marco Nervo ${ }^{3}$, Nadia Pastrone ${ }^{1}$, \\ Francesco Prino ${ }^{1}$, Luciano Ramello ${ }^{4}$, Massimo Ravera ${ }^{3}$, Chiara Ricci ${ }^{2,3}$, Alessandra Romero ${ }^{1,2}$, Roberto Sacchi ${ }^{1,2}$, \\ Amedeo Staiano ${ }^{1}$, Lorenzo Visca ${ }^{1,2}$ and Lorenzo Zamprotta ${ }^{1,2}$
}

\begin{abstract}
Introduction: X-ray computed tomography $(\mathrm{CT})$ is now used in the cultural heritage field because it is non-invasive and it can give a large amount of information on the inner structure of the object under study. Until recently mainly medical CT scanners or micro-CT setups have been used, limiting the analysis to relatively small artworks or requiring multiple acquisition and difficult image-joining for objects larger than detector dimensions.

Results: To overcome the limitations of ordinary CT devices, a facility for the X-ray tomography of large size artefacts has recently been designed and installed in a protected area of the Fondazione Centro Conservazione e Restauro "La Venaria Reale", a Centre for Preservation and Restoration. This facility, based on a X-ray source, a linear X-ray detector and a high precision mechanical system, has been and will be used to gather information on materials, manufacturing techniques and conservative conditions of artworks undergoing the restoration process.

In this paper the results of the tomography of the first analyzed large artistic object are presented, giving an idea of the wealth of information obtained from the CT scan. The presented artwork is the writing cabinet called "doppio corpo", a masterpiece of furniture more than $3 \mathrm{~m}$ high, inlaid for Savoy Residences by Pietro Piffetti, the most famous cabinet-maker in Piedmont in the XVIII century. The artwork is now housed in the Quirinale Palace, the official residence of the Italian President in Rome.
\end{abstract}

Conclusions: The $C T$ analysis permitted us to obtain valuable information about the conservative conditions, the presence of previous interventions, the distribution of various materials and the dimensions and arrangement of several wooden pieces, thus allowing for interesting hypotheses about the building technique of this masterpiece.

Keywords: X-rays, Computed tomography (CT), Cultural heritage, Cabinetmaking, Pietro Piffetti

\section{Introduction}

$\mathrm{X}$-ray imaging techniques are widely used in the cultural heritage field because they are non invasive [1]. Among these Computed Tomography $(\mathrm{CT})$ allows one to obtain a large amount of information on the inner structure of the artistic object under study [2,3]. Depending on the material and the dimensions of the object to be analysed, different approaches can be chosen. Mummies and

\footnotetext{
* Correspondence: alessandro.re@unito.it

'Istituto Nazionale di Fisica Nucleare, Sezione di Torino, via Pietro Giuria 1, 10125 Torino, Italy

2Dipartimento di Fisica, Università di Torino, via Pietro Giuria 1, 10125 Torino, Italy

Full list of author information is available at the end of the article
}

objects of similar dimensions and material composition are usually analysed with medical CT scanners [4]. These devices, being developed and optimised to analyse a human being, show strong limitations when applied to the cultural heritage field. First, the dimension of the analysed object cannot be larger than a human body and also the material has not to be too dense; moreover, due to the limitation on dose which can be delivered in a medical CT, the signal is typically quite low and for this reason the resolution limited. The voxel side is usually around $0.5 \mathrm{~mm}$, even if for some special cases ("region of interest" tomography) values around $0.2 \mathrm{~mm}$ can be 
reached [5]. For this reason, especially in the last years, different approaches have been used and custom setups have been developed: for very small objects [6] or when very high resolution is required [7], micro-CT has to be used, usually exploiting synchrotron radiation. Another approach to obtain good results without a large-scale facility is to develop a customized system based on a Xray tube and a flat panel detector. They can be designed to analyse small objects [8] or larger ones [9], but, because of the detector dimensions, large areas cannot be acquired in a single radiograph and the joining of many images together is required (tile scanning).

To overcome the limitations of both medical scanners and of the systems based on flat panel detectors, in the framework of the neu_ART regional project [10], we developed a versatile $C T$ system based on a linear detector moved by a high precision mechanics allowing us to obtain a radiograph up to $3.5 \mathrm{~m}$ wide and $0.5 \mathrm{~m}$ high in few tenths of seconds. Combining radiographs acquired at different angles the 3D-CT reconstruction is then obtained. The prototype of this instrument has been installed in a protected area of the Fondazione Centro Conservazione e Restauro "La Venaria Reale" (CCR), a Centre for Preservation and Restoration. The CCR is an institute of training and research organized in different department: the school of advanced training, conservation an restoration laboratories, scientific and imaging laboratories, documentation centre and shelves. In cooperation with the University of Turin, in the CCR takes place a five-years degree course in Preservation and Restoration of Cultural Heritage. Thanks to this strategic location and to the number of artworks that pass through the CCR to be studied and restored, the radiotomographic instrument is now routinely employed to perform X-ray imaging of artefacts up to large sizes [11,12]: objects up to $4 \times 3.5 \mathrm{~m}^{2}$ can be analysed by means of radiography (mainly paintings, both on canvas and on wood) while artworks that can be inscribed in a cylinder up to $2.5 \mathrm{~m}$ in diameter and $2.7 \mathrm{~m}$ high can be $\mathrm{CT}$ scanned. This instrument is becoming an irreplaceable tool for restorers' work: in fact the obtained images provide valuable information on materials, manufacturing techniques and conservative conditions of the analysed artworks. The result of a CT is a $3 \mathrm{D}$ reconstruction of the analysed object in which each point is represented through a grey level, proportional to the X-rays absorption, i.e. related to the density and atomic number of the crossed material. Thanks to this property one can distinguish all the parts composing an artwork, how they are joined, what is their state of preservation (for example, for wooden artworks, the holes created by xilofagous insects can be highlighted) and also make some hypothesis about the presence of different materials, even if not their identification.
In this paper the results of the first $\mathrm{CT}$ of a precious large object performed with this prototype are presented: it is the writing cabinet with a fall-front desk in lower body and a two doors shelves in the top shown in Figure 1, also known as "doppio corpo", a masterpiece of furniture inlaid for Savoy Residences by Pietro Piffetti, the most famous cabinet-maker in Piedmont in the XVIII century, and now housed in the Quirinale Palace, the official residence of the Italian President in Rome [13].

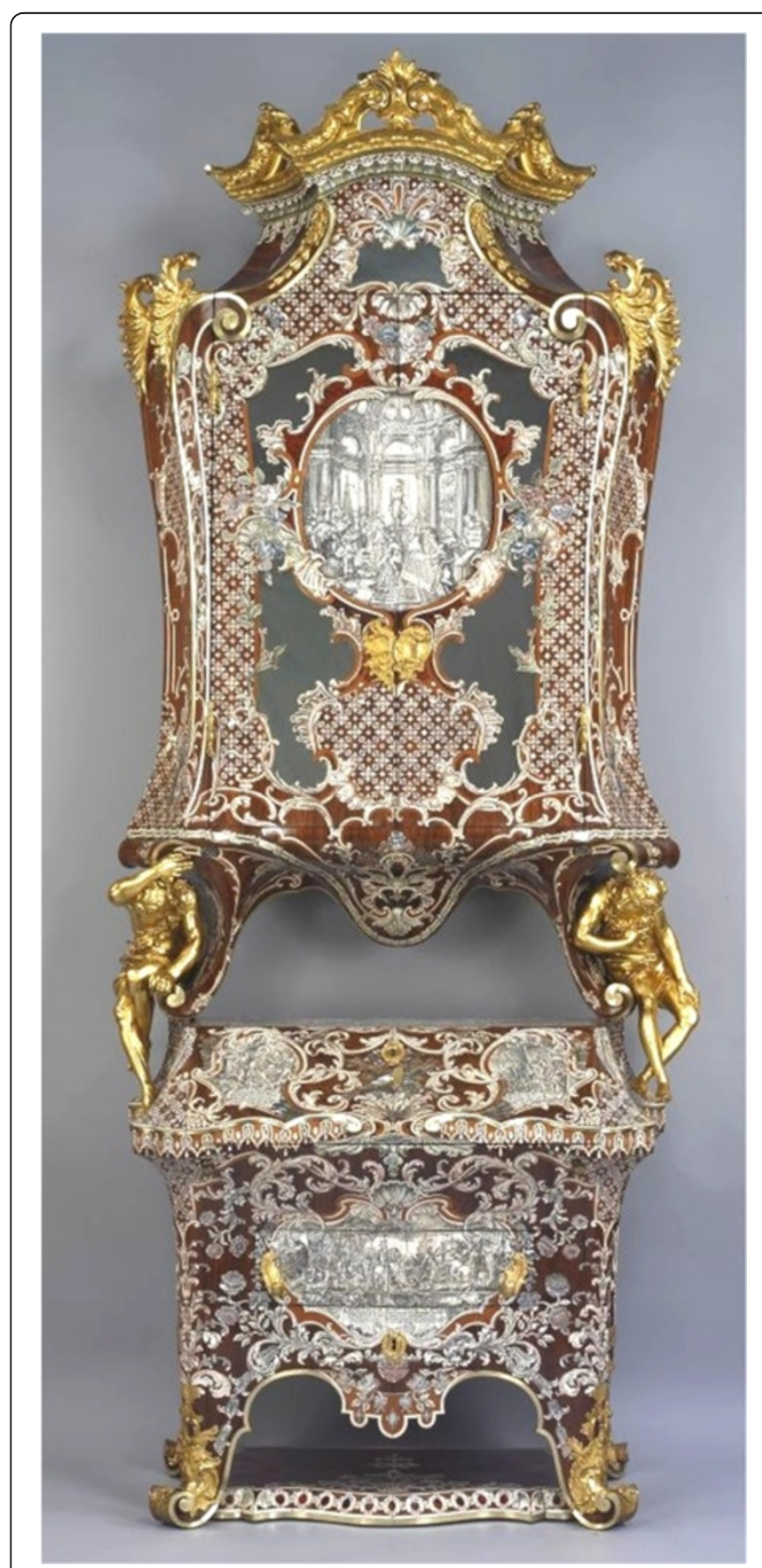

Figure 1 The artwork. The wooden writing cabinet called "doppio corpo" by Pietro Piffetti (XVIII century) housed in the Quirinale Palace. It is composed by a lower part (fall-front desk), an upper part (shelves) and two lateral golden wood sculptures ("Telamons"). 
The interest in performing a $\mathrm{CT}$ on such a large object, whose height is above $3 \mathrm{~m}$, is to better understand the inner structure and the manufacturing technique used by Pietro Piffetti to realize one of his masterpieces. In fact this information cannot be obtained by means of visual inspection or other non-invasive techniques, because the wooden structure is completely hidden behind the precious inlay. The CT images allow one to highlight the distribution of various materials such as different types of woods and metals, ivory, etc. The dimensions and arrangement of the hidden wooden pieces used by the author can also be examined. Moreover it is possible to plan restorations or interventions in a more accurate way, thanks to the fundamental information about the conservative conditions, the structural weaknesses, the presence of previous interventions and the possible future alteration due to hygrometric changes. In fact, because the wood is hygroscopic and it shows a strong directional anisotropy, it reduces and dilates in different way depending on the orientation of the cut: minimum variation in axial direction (parallel to the trunk axis), medium variation in radial direction (orthogonal to the trunk axis) and maximum variation in tangential direction (orthogonal to both the previous ones). This fact can be very important if wooden blocks are joined together because, depending on their orientation, an hygrometric change can cause disassembling or fractures. For these cases a strict hygrometric control is fundamental for the preservation of the artworks.

\section{The artwork}

Pietro Piffetti was one of the most famous European cabinetmakers of the eighteenth century. He was born in Turin in 1701 and worked at Savoy court at that time. The artwork analysed in this paper is one of his masterpieces: the writing cabinet called "doppio corpo", part of the collections of Quirinale Palace in Rome. This is a very important and precious artwork that arrived in Rome in 1889, after the unification of Italy and the transfer of the Royal Capital City from Turin (1861) to Rome (1871). The writing cabinet was realized for royal apartments in Turin, probably in the 40s of XVIII century, and it is made of exotic woods, polychrome ivories, nacre, tortoiseshell. Its dimensions are $312 \times 128 \times$ $62 \mathrm{~cm}^{3}$ and it is composed by a lower part, with a fallfront desk, nine small drawers inside and two drawers under fall-front; and by an upper part composed by shelves with two legs (called "alzata"), four shelves and two inlayed doors. Two golden wood statues adorn the sides of this artwork: a male statue representing the Autumn and a female statue representing the Summer. Nine ivory engraved plaques, inlayed in the surface, reproduce Otto Venius' engraves of Horatio's "Emblemata" with lyric mottos. During the last years, many historical and technical studies have examined the decorative apparatus' iconography of the cabinet because in the 2011, in occasion of exhibition "La Bella Italia" in Venaria Royal Palace the writing cabinet was restored by CCR. For this activity the CCR had realized some technical study about the structure and the decoration of Piedmonts' cabinetmaking of XVIII century [14,15].

\section{Experimental setup}

The tomographic system used for the CT scan of this artwork is the prototype of the scanner developed within the neu_ART project which, apart from minor differences in some mechanical parts, has the same functionality and performance as the final installation [16]. It has been designed and developed to be flexible enough to analyse artworks of varying constituting materials and up to large sizes, which can be inscribed in a cylinder up to $2.5 \mathrm{~m}$ in diameter and $2.7 \mathrm{~m}$ in high. The distinctive and unique feature of this instrument, which makes it rather attractive for analysing large objects, is the possibility to cover a large area in a single radiograph, thus avoiding tile scanning of the object. Its location inside a Centre for Preservation and Restoration eliminates any need for dangerous and costly transportations to external facilities.

The CT system comprises an X-ray source, a rotating platform where the artwork is positioned and a digital linear X-ray detector which scans the projection plane through a high precision mechanical system. Two computers allow one to control and synchronize all the movements and to acquire the radiographs.

The X-ray source is a General Electric Eresco 42MF4 with tungsten anode and maximum tube voltage and power of $200 \mathrm{kV}$ and $900 \mathrm{~W}$ respectively. A $2 \mathrm{~mm}$ thick aluminium slab is placed just outside the tube exit window to absorb the softer X-rays and limit the beamhardening effects [17]. The tube is air cooled and it has been used with cycles of 40 minutes of irradiation and 20 minutes of cooling to avoid excessive overheating.

The detector is a Hamamatsu X-ray Line Sensor Camera C9750-20TCN composed by a scintillator coupled with a linear array of CCDs arranged vertically. To protect the electronics from radiation damage, it is shielded with $1 \mathrm{~cm}$ thick lead slab leaving a thin aperture matching the sensitive area. For the acquisition of each projection, the detector is translated horizontally at uniform speed and rotated around the vertical axis in order to be always oriented toward the focal spot of the X-ray source and to reduce Compton scattered X-rays, improving the image quality. An external signal synchronized with the horizontal movement is provided to trigger the acquisition of each vertical line of the image. The rotating platform is designed to carry large objects in a stable way and is 
connected to a Newport RV350PE rotary stage providing small and very precise angular steps.

All the equipment is installed in an area of $6 \times 5 \mathrm{~m}^{2}$ shielded accordingly to radiation protection rules and is operated remotely. The procedure for the acquisition of all the projections, a sequence of horizontal scans of the detector, each followed by a rotation of the object, is fully automated. For the analysis of large objects, the projections of portions at different heights are achieved by varying the height of both the X-ray source and the detector and repeating the whole procedure.

More information and details about the instrument and the experimental setup are reported in Table 1. The lower part of the artwork, in the following called "fallfront desk", has been separated from the upper part, composed by the shelves and from the two lateral statues and each of these parts was analyzed separately. They were further subdivided in horizontal portions, 4 for the fall-front desk, 7 for the shelves and 1 for each statue, for a total of 13. In Figure 2 the frontal radiography of all the joined portions is presented. The objectdetector distance was chosen as the minimum achievable, considering the large size of the objects, to minimize the penumbra, while the source-detector distance was set as

\begin{tabular}{ll} 
Table 1 Details of the experimental setup \\
\hline Artwork dimensions & $129 \times 59 \times 312 \mathrm{~cm}^{3}$ \\
Source-Detector Distance (SDD) & $2.95 \mathrm{~m}$ \\
Source-Object Distance (SOD) & $2.14 \mathrm{~m}$ \\
Object-Detector Distance (ODD) & $0.81 \mathrm{~m}$ \\
Magnification & $\times 1.38$ \\
Detector pixel size & $0.2 \mathrm{~mm}$ \\
Binning & $4 \times 4$ \\
Image pixel size & $0.8 \mathrm{~mm}$ \\
Reconstructed voxel size & $0.58 \mathrm{~mm}$ \\
Tube voltage & $180 \mathrm{kV}$ \\
Current & $5 \mathrm{~mA}$ \\
Focal spot size & $3 \mathrm{~mm}$ \\
Detector scan speed & $5 \mathrm{~m} / \mathrm{min}$ \\
Horizontal portions & 13 \\
Number of projections/portion & 720 \\
Total number of projections & 9360 \\
Scanned area & $2.1 \times 0.5 \mathrm{~m}{ }^{2}$ \\
Image dimensions & $10500 \times 2560 \mathrm{pixel}^{2}$ \\
Output & $12 \mathrm{bit}$ \\
Image size & $51.3 \mathrm{MB}$ \\
Disk space & $437 \mathrm{~GB}$ \\
Average acquisition time for each portion & $10 \mathrm{hours}$ \\
Total time & $5.6 \mathrm{days}$ \\
\hline
\end{tabular}

the minimum comprising the largest width of the object in the X-ray beam, thus maximizing the signal intensity.

For each portion 720 projections have been acquired, one each $0.5^{\circ}$ of rotation of the object. A non rotating marker was added in the image field to allow for checking and refining the horizontal alignment of all the projections. Moreover, several open beam and dark images have been acquired for later use in the image processing stage. The CT reconstruction was performed with a noncommercial software-utility developed by Dan Schneberk of Lawrence Livermore National Laboratory (USA), using the approximation of fan beam geometry and the filtered back-projection algorithm [17].

\section{Results and discussion}

The main aim of the CT analysis of the writing cabinet was to obtain information about its internal structure, its building technique, the conservative conditions and the presence of previous repairs and restorations. Most of the results, obtained in an absolute non-invasive way by means of CT, reveal details impossible to be highlighted by means of other techniques or without dismantle the artwork. To identify and locate some details, a comparison among photographs, radiographs and CT results (3D rendering and both horizontal and lateral sections) is very useful and sometimes absolutely necessary. Several examples are reported in the following and have been divided in three topics: building technique, conservative conditions, previous interventions.

\section{Building technique}

The external shaped sides of the upper part (shelves) have no correspondence with the inner squared structure as shown in Figure 3a. From the radiograph (Figure 3b) these parts seem not to be filled and this hypothesis is confirmed by the CT reconstructed sections, as shown in Figure 3c. However three triangular spacers are identified, inserted in a groove hollowed out in the external side of the shelves, a type of joint called "a canale passante" (Figures 3d, e).

One of the more interesting parts of the upper part is the central oval ivory plate, supported by the left door. In the CT horizontal sections of Figure 4, three different constituent layers can be clearly distinguished: from the outside the ivory veneer, about half $\mathrm{cm}$ thick, a thin wooden layer of about one $\mathrm{cm}$ thickness, followed by the wooden support of the door.

The internal structure of the lower part (fall-front desk), shown in Figure 5a, is quite complex, with secret drawers and several openings, as can be seen from a CT horizontal section shown in Figure 5b: two drawers have a double bottom which hides additional small drawers enclosed in lateral niches drawn in the sides. A CT reconstructed section of the shaped sides of the fall-front 


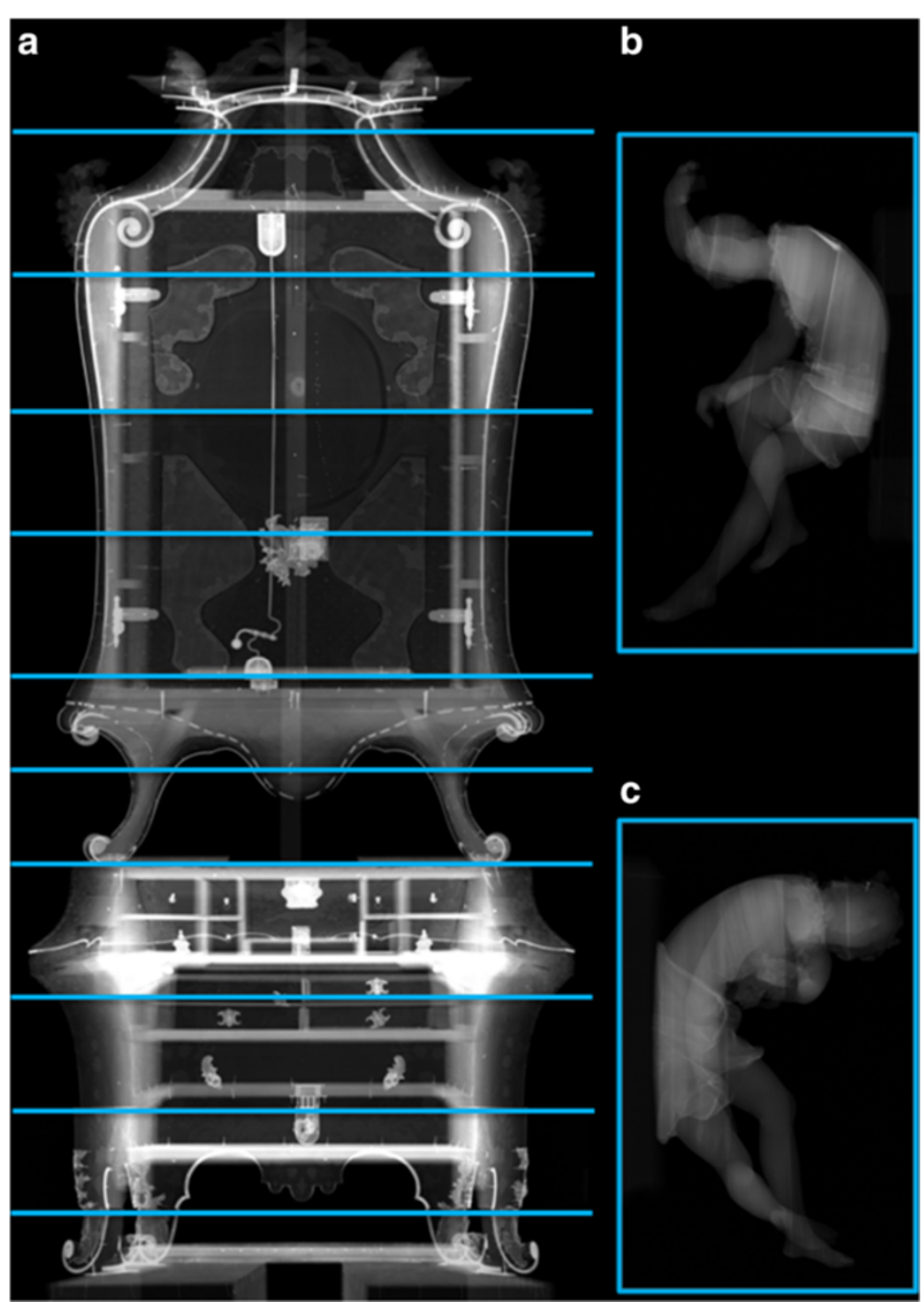

Figure 2 X-ray radiography. Frontal X-ray radiographs of the writing cabinet by Pietro Piffetti; the 13 portions for the CT reconstruction are highlighted (11 for the main part of the artwork (a) and 2 for the statues (b and $\mathbf{c})$ ).

desk is shown in Figure 5c. They appear as not being made from a single piece of wood, but rather composed by a stack of wooden blocks arranged to give the peculiar shape to the artwork. In Figure 5d these peculiar technique have been highlighted, using a different colour for each block. The wood grain of each block is visible allowing one to determine wooden planes with different arrangements: radial, tangential and transversal. Between these blocks a rectangular cavity, few centimetres wide, appear on each side: these are weak points for mechanical stresses, especially in the right side where this cavity reaches the thin external veneer.

In the CT reconstruction of both the middle and the lower part, some of the wooden blocks are brighter than others. An example can be seen in Figure 5c and in Figure 5d, where the two brighter blocks have been highlighted in red. This indicates the use of different species of wood. In other artworks realised by the same author, a similar feature has already been observed: usually the main part of the furniture was made in poplar and few structural parts were made from walnut [18]. Even if for this artwork a wooden analysis have not been performed and from CT images it is not possible to define which kind of wood was used, the comparison among the CT data and the information on the constructive technique used by the same author allows to make some hypothesis: the main part of the furniture was probably made with poplar wood (density of seasoned wood: $0.45 \mathrm{~g} / \mathrm{cm}^{3}$ ), while few blocks was made with walnut wood (density of seasoned wood: $0.6 \mathrm{~g} / \mathrm{cm}^{3}$ ). These few blocks, that are brighter in the CT sections, in the fallfront desk are placed at the four corners (as shown in 


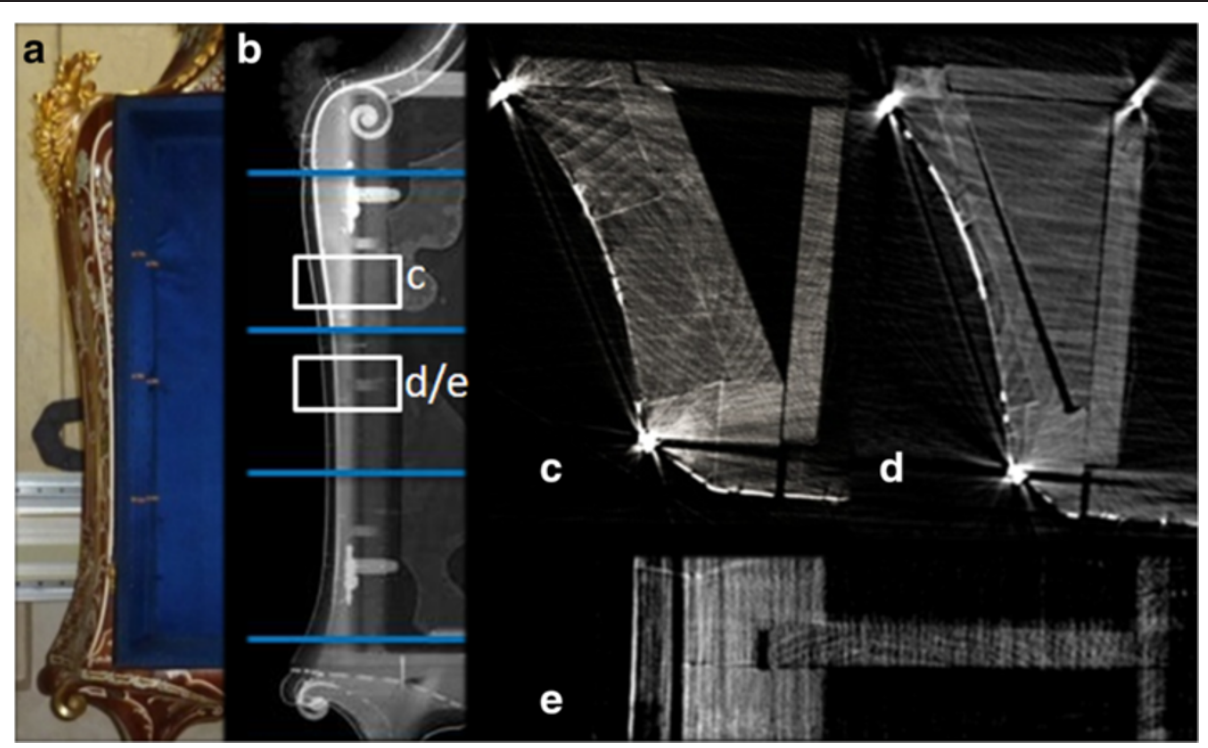

Figure 3 The side of the shelves. (a) the shaped side of the shelves; (b) X-ray radiograph of the same part; CT horizontal section without (c) and with (d) a triangular spacer; (e) $\subset T$ lateral section of the spacer.

Figure $5 \mathrm{c}$ and d) and provide the load-bearing structure of the cabinet.

In Figures $6 \mathrm{a}$ and $\mathrm{d}$ the two lateral wooden statues are presented. Thanks to the CT reconstruction their inner structure are clearly visible in Figures $6 \mathrm{~b}$ and e, where each wooden block have been virtually coloured with a different colour. Both the statues are composed by many parts pasted together, respectively 8 for the Autumn (Figure 6b) and 9 for the Summer (Figure 6e). The wood grain of these parts are differently arranged suggesting that each statue was obtained by pasting to a main block smaller and smaller pieces, one after the other, which were later carved to reach the final shape. Other interesting findings, impossible to be seen from the outside because of the gilded layer covering the statues, are shown in Figures 6c and f: they are a big knag in the Autumn (Figure 6c) and a nail in the head of the Summer (Figure 6f).

An important insight into the building technique used by the artist is obtained by the analysis of the joints. Figure 7 shows few examples of the different types of joint observed: "tonguings", "cogs" and "cog and groove", in addition to the joint "a canale passante" already shown in Figure 3e. As resulting from studies of other artworks from the same artist [18], Pietro Piffetti is known for having used a complex and elaborate structure for the realisation of furniture. The large variety of joints used in the same artwork is yet another confirmation, showing a structure of this writing cabinet even more complex than the ones already known.

\section{Conservative conditions}

The CT reconstruction allows one to provide highlights on the conservative conditions of some parts of this artwork which are not accessible to visual inspection. In the CT image shown in Figure 4a many longitudinal fractures of the oval ivory plate can be clearly detected: they are typical of this material and they are partially visible already from the external observation, but only with a CT reconstruction is possible to understand how deep they are.

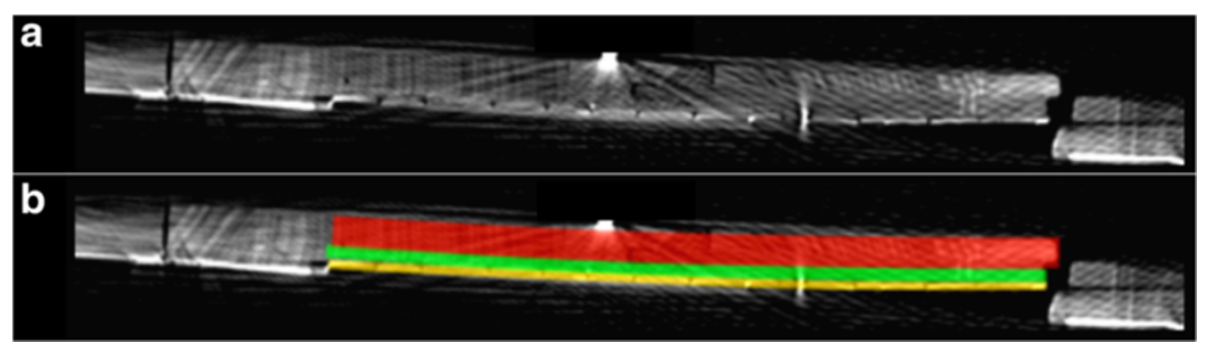

Figure 4 The central ivory plate. (a) CT horizontal sections of the central oval ivory plate of the shelves; (b) the three different layers highlighted: the ivory veneer (yellow), the thin wooden layer called "supportino" (green) and the wooden support (red). 


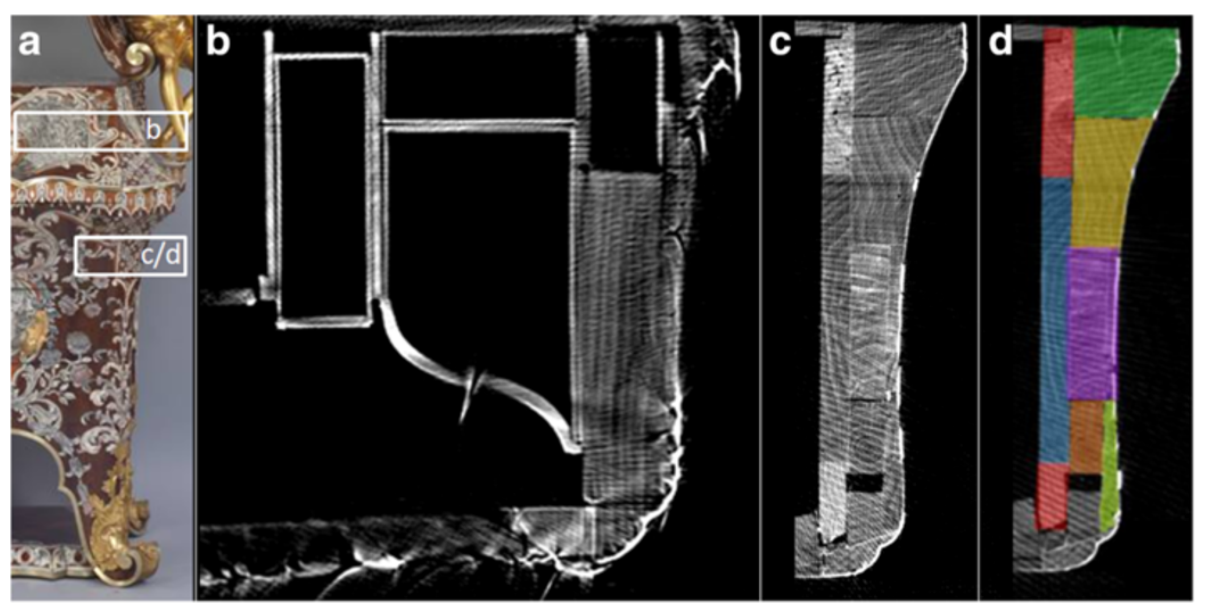

Figure $\mathbf{5}$ The side of the fall-front desk. (a) the shaped side of the fall-front desk; (b) CT horizontal section showing secret drawers and opening; (c) CT horizontal section showing a rectangular cavity and holes of xylophagous insects in the brighter blocks (probably walnut wood); (d) the different wooden blocks highlighted (in red the walnut wood ones).

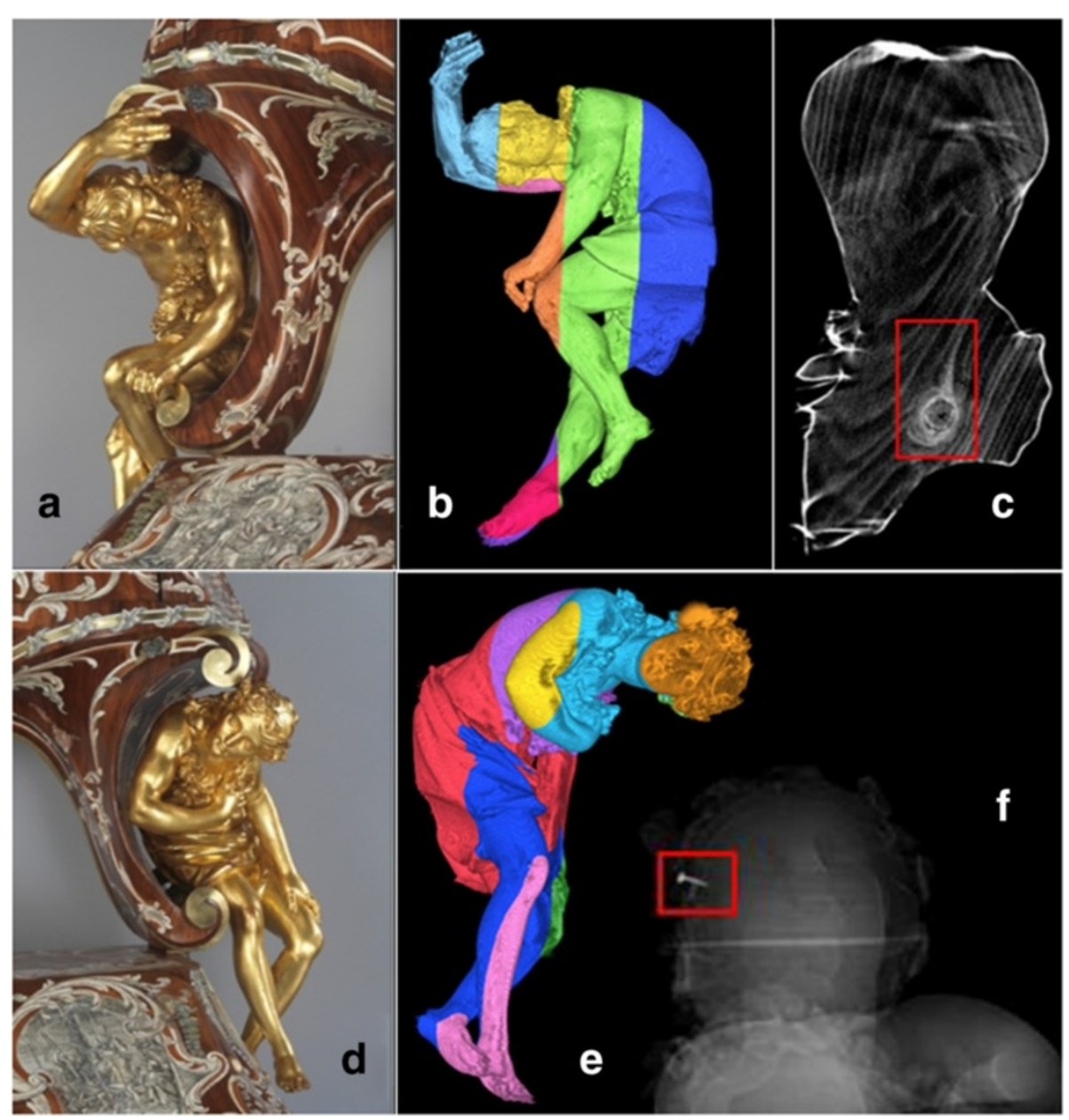

Figure 6 The lateral statues. The two lateral wooden statues: (a) the Autumn and (d) the Summer; (b) and (e): CT reconstruction with various blocks highlighted in different colours; (c) CT horizontal section of the Autumn showing a big knag; (f) X-ray radiograph of the Summer showing a nail in the head. 


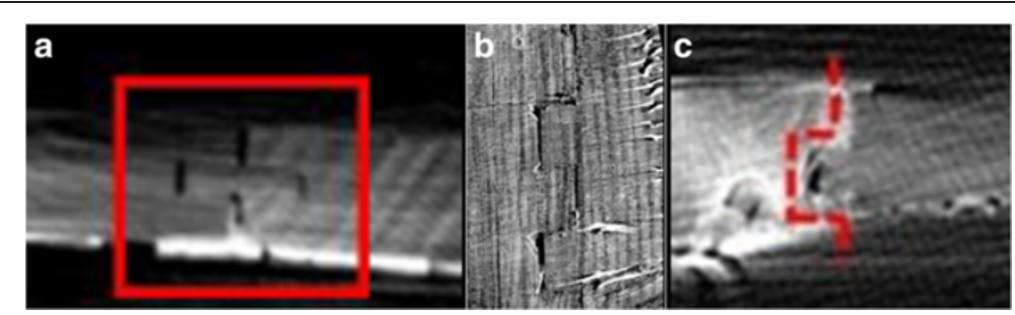

Figure 7 Joints. Different kinds of joint: (a) CT horizontal section of the door with tonguings; (b) CT lateral section of the back side of the oval plate formed by two wooden pieces joined by cogs; (c) CT horizontal section of the fall-front in the fall-front desk, showing a joint with cog and groove.

In Figure 5c the brighter blocks show holes and tunnels left by xylophagous insects strikes. The same information have been detected both in horizontal and lateral CT sections related to other parts of the artwork; in particular the upper ornament of the shelves and the sides and the drawers of the fall-front desk appear to be quite deteriorated. This information, obtained in a non invasive way, can be very useful when the conservation status of a wooden artwork is required: in fact this attacks are often not detectable from the outer surface and, like in this case, they can strike some structural and important parts.

\section{Previous interventions}

Figure $8 \mathrm{a}$ is a radiograph showing two screws in the lower part of the shelves. The shape of these screws and of others located in the bottom part of the drawers, is different and more recent than the shape of the screws employed by Pietro Piffetti in other artworks.

In Figure $8 \mathrm{~b}$ some of the longitudinal fractures of the ivory plate in the shelves door are shown. A radiograph of this part (Figure 8c) shows that one of these fractures was deeper and reached the thin wooden layer called "supportino". This crevice was repaired by inserting a row of small nails (alternatively from the exterior to the interior and vice versa), invisible both from the outside and the inside.

These are just two examples showing previous repairs and restoration activities performed on the writing cabinet that can be detected using a CT scan.

\section{Conclusions}

The successful application of a new X-ray tomography instrument on a precious artwork of big dimensions and composed by different materials has been presented. This non invasive analysis provides valuable information about the building technique, the conservative conditions and the presence of previous restorations.

In particular it allows to highlight the types and structure of the joints and assemblies and to evaluate the dimensions and the arrangements of the building pieces used by the artist. In the upper part the shaped sides reveal to be hollow, except for the presence of three spacers, while in the lower part they reveal to be formed by different wooden blocks. Moreover, in the lower part, a complex structure with secret drawers and opening is highlighted. The two statues decorating this artwork appear to be made by many pieces of wood.

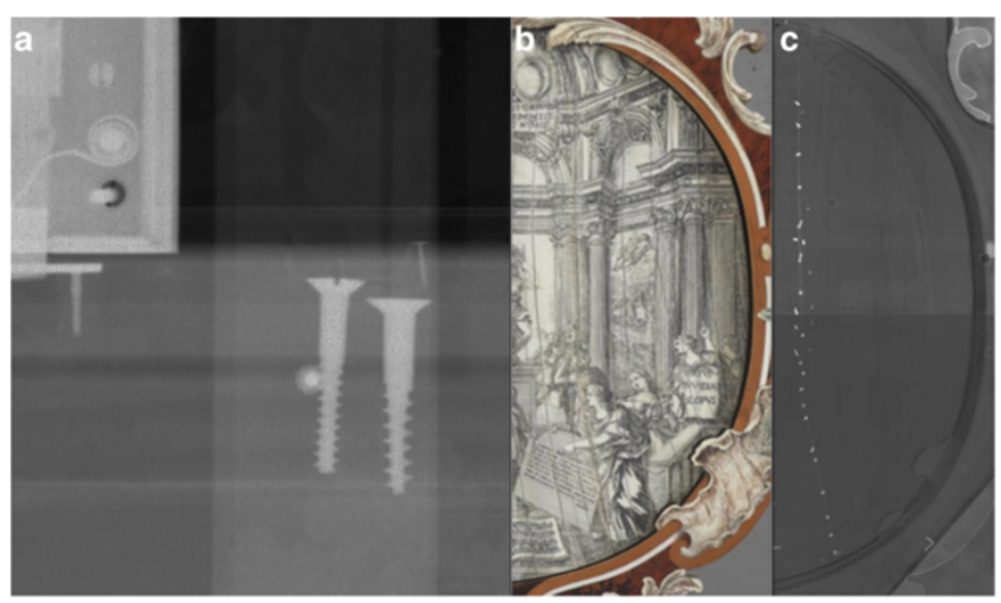

Figure 8 Previous interventions. Previous interventions: (a) X-ray radiograph of the screws in the lower part of the shelves; (b) detail of the ivory plate and (c) its X-ray radiograph showing a row of nails to fix a crevice of the thin wooden layer called "supportino". 
Different kinds of material are detected and precisely located on the artworks. The overall conservative status is good, but previous repairs and some xylophagous insect holes are detected. The $\mathrm{CT}$ analysis demonstrates to be the only available method to obtain this kind of important and unique information on such an artwork, to help the art historians, the conservators and the restorers in their own work.

\section{Competing interests}

The authors declare that they have no competing interests.

\section{Authors' contributions}

All authors contributed to the planning, design and construction of the equipment. ARe, FA, CA, JC, ALG, GM, MN, NP, CR, RS performed the data acquisition. $A R e, R B, C R$ performed the data analysis. $A R e, M R, C R$ interpreted $X$-ray imaging. SDB studied the art historical context. MR studied the technical context of XVIII century. ARe, CR wrote the manuscript and all authors revised it critically. All authors read and approved the final manuscript.

\section{Acknowledgements}

This study was carried out in the framework of the neu ART research project funded by Regione Piemonte. We thank the administrative staff for the precious support: D. Bortot (INFN), A. Bellino and M. Giacoia (CCR) and G. Sbarrai (Università di Torino). We also thank for their valuable work the team of the Technological Laboratory of INFN Torino, in particular S. Brasolin, F. Borotto, G. Ferrero and R. Panero. We are grateful to L. Godart, director of Quirinale Palace Art Collections, and to his staff, in particular way L. Morozzi for supporting the experimental application of $C T$ on Pietro Piffetti's "Doppio Corpo" and to F. Casali, M.P. Morigi, M. Bettuzzi and D. Schneberk for the fruitful discussions and the much useful advice.

\section{Author details}

'Istituto Nazionale di Fisica Nucleare, Sezione di Torino, via Pietro Giuria 1 10125 Torino, Italy ${ }^{2}$ Dipartimento di Fisica, Università di Torino, via Pietro Giuria 1, 10125 Torino, Italy. ${ }^{3}$ Centro Conservazione e Restauro "La Venaria Reale", Piazza della Repubblica, 10078 Venaria Reale, Torino, Italy. ${ }^{4}$ Dipartimento di Scienze e Innovazione Tecnologica, Università del Piemonte Orientale, Viale Teresa Michel 11, 15121 Alessandria, Italy.

Received: 7 April 2014 Accepted: 31 August 2014

Published online: 11 September 2014

\section{References}

1. Alfeld M, Broekaert JAC: Mobile depth profiling and sub-surface imaging techniques for historical paintings - a review. Spectrochimica Acta Part B 2013, 88:211-230.

2. Casali F: X-Ray and Neutron Digital Radiography and Computed Tomography. In Physical Techniques in the Study of Art, Archaeology and Cultural Heritage - vol 1. Edited by Creagh D, Bradley D. New York: Elsevier; 2006:41-123.

3. Bettuzzi M, Brancaccio R, Casali F, Cornacchia S, Giordano M, Morigi MP, Pasini A, Romani D: Innovative systems for Digital Radiography and Computed Tomography: Applications to Cultural Heritage Diagnostics. In Physics Methods in Archaeometry. Edited by Martini M, Milazzo M, Piacentini M. Amsterdam: los Press; 2004:461-470.

4. Huppertz A, Wildung D, Kemp BJ, Nentwig T, Asbach P, Rasche FM, Hamm B: Nondestructive insights into composition of the sculpture of Egyptian queen Nefertiti with CT. Radiology 2009, 251(1):233-240

5. Logan $\mathrm{H}$, Wolfaardt J, Boulanger $\mathrm{P}$, Hodgetts $\mathrm{B}$, Seikaly $\mathrm{H}$ : Evaluation of the accuracy of cone beam computerized tomography (CBCT): medical imaging technology in head and neck reconstruction. J Otolaryngol Head Neck Surg 2013, 42:25.

6. Zhang X, Blaas J, Botha C, Reischig P, Bravin A, Dik J: Process for the 3D virtual reconstruction of a microcultural heritage artifact obtained by synchrotron radiation $\mathrm{CT}$ technology using open source and free software. J Cult Heritage 2012, 13:221-225.

7. Sodini N, Dreossi D, Chen R, Fioravanti M, Giordano A, Herrestal P, Rigon L, Zanini F: Non-invasive microstructural analysis of bowed stringed instruments with synchrotron radiation X-ray microtomography. J Cult Heritage 2012, 13(3):S44-S49.

8. Tuniz C, Bernardini F, Cicuttin A, Crespo ML, Dreossi D, Gianoncelli A, Mancini L, Mendoza Cuevas A, Sodini N, Tromba G, Zanini F, Zanolli C: The ICTP-Elettra X-ray laboratory for cultural heritage and archaeology. Nuclear Instr Methods Physics Res Sec A 2013, 711:106-110.

9. Morigi MP, Casali F, Bettuzzi M, Brancaccio R, D'Errico V: Application of $\mathrm{X}$-ray computed tomography to cultural heritage diagnostics. Applied Physics A 2010, 100:653-661.

10. Re A, Albertin F, Bortolin C, Brancaccio R, Buscaglia P, Corsi J, Cotto G, Dughera G, Durisi E, Ferrarese W, Gambaccini M, Giovagnoli A, Grassi N, Lo Giudice A, Mereu P, Mila G, Nervo M, Pastrone N, Petrucci F, Prino F, Ramello L, Ravera M, Ricci C, Romero A, Sacchi R, Staiano A, Visca L, Zamprotta L: Results of the Italian neu_ART project. IOP Mat Sci Eng (MSE) Conf proc Series 2012, 37:012007.

11. Buscaglia P, Corsi J, Nervo M, Ricci C: Digital radiography as a support tool in knowledge and definition of intervention guidelines: House of Savoy Portraits in Racconigi Castle. In I/ Progetto neu_ART. Studi e applicazioni/ Neutron and X-ray Tomography and imaging for Cultural Heritage, Cronache 4. Edited by Nervo M. Torino: Editris; 2013:77-87.

12. Capezio R, Luciani P, Re A, Ricci C, Spagnolo M, Tasso V: Computed tomography applied to cabinet making wooden furniture: the "Doppio corpo" by Piffetti at Quirinale Palace. In II Progetto neu_ART. Studi e Applicazioni/Neutron and X-ray Tomography and Imaging for Cultural Heritage, Cronache 4. Edited by Nervo M. Torino: Editris; 2013:92-103.

13. Cifani A, Monetti F: Fonti iconografico-letterarie e metodologia di lavoro dell'ebanista torinese Pietro Piffetti. Contributi documentari per la sua vita e scoperte per il cassettone a ribalta del Palazzo del Quirinale ed altri mobili. Bollettino d'arte 2005, 131:23-52.

14. Spantigati CE, De Blasi S: I/ Restauro Degli Arredi Lignei. Firenze: L'ebanisteria piemontese. Studi e ricerche. Edited by Nardini; 2011.

15. Morozzi L: Pietro Piffetti, Cassettone a Ribalta con Scansia a due ante. In La Bella Italia. Arte e Identità delle città capitali, Catalogue of Exhibition, Venaria Reale, 17 March - 11 September 2011. Edited by Paolucci A. Silvana: Milano; 2011:172

16. Re A, Brancaccio R, Corsi J, Cotto G, Dughera G, Ferrarese W, Grassi N, Lo Giudice A, Lusso S, Mereu P, Mila G, Nervo M, Pastrone N, Ricci C, Sacchi R, Visca L, Zamprotta L: The radio-tomographic apparatus. In I/ Progetto neu_ART. Studi e Applicazioni/Neutron and X-ray Tomography and Imaging for Cultural Heritage, Cronache 4. Edited by. Torino: Editris; 2013:19-42.

17. Kak AC, Slaney M: Principles of Computerized Tomographic Imaging. Edited by: IEEE Press, Piscataway, NJ; 1988

18. De Blasi S, Nervo M, Ravera M, Spantigati C: Structural characters of Piedmontese eighteenth-century cabinetmaking: historical documents, restorations and new technologies. The Centro Conservazione e Restauro 'La Venaria Reale'. In Restoring Joints, Conserving Structures. Proceedings of the Tenth International Symposium on Wood and Furniture Conservation. Edited by Vasques Dias M. Amsterdam: Stichting Ebenist; 2010:98-107.

\section{doi:10.1186/s40494-014-0019-9}

Cite this article as: Re et al: X-ray tomography of large wooden artworks: the case study of "Doppio corpo" by Pietro Piffetti. Heritage Science 2014 2:19.

\section{Publish with ChemistryCentral and every scientist can read your work free of charge \\ "Open access provides opportunities to our colleagues in other parts of the globe, by allowing anyone to view the content free of charge." W. Jeffery Hurst, The Hershey Company.}

- available free of charge to the entire scientific community

- peer reviewed and published immediately upon acceptance - cited in PubMed and archived on PubMed Central

- yours - you keep the copyright

Submit your manuscript here

http://www.chemistrycentral.com/manuscript/<smiles>c1ccccc1</smiles>
Chemistry Central 